\title{
In an era of health reform: Defining cost differences in current esophageal cancer management strategies and assessing the cost of complications
}

\author{
MadhanKumar Kuppusamy, MD, Julie Sylvester, MPA, and Donald E. Low, FACS, FRCS(c)
}

Objective: Outcomes assessing various treatment modalities for esophageal cancer primarily report results in terms of morbidity, mortality, survival, and quality of life. The most appropriate stage-by-stage treatment for esophageal cancer remains controversial. There are limited data outlining the comparative costs of surgical, combined modality and definitive chemoradiation treatments, and added costs associated with complications.

\begin{abstract}
Methods: Between 2000 and 2004, 4 treatment groups were studied: surgery alone, chemotherapy followed by surgery, chemoradiotherapy followed by surgery, and chemoradiotherapy alone. Fifteen consecutive patients from each group receiving their entire treatment at Virginia Mason Medical Center were identified. Patient demographics and outcomes were taken from a prospective institutional review board-approved surgical database, and chart review obtained information for neoadjuvant therapy and definitive chemoradiotherapy groups. Treatment-related costs were extracted from Virginia Mason Medical Center's financial data management system between date of diagnosis to 90 days after completion of primary therapy.
\end{abstract}

Results: Treatment groups were similar in age, gender ratio, American Society of Anesthesiologists status, body mass index, and tumor cell type. Costs increased with the number of treatment modalities: surgery alone, $\$ 33,517$; chemotherapy followed by surgery, $\$ 41,875$; chemoradiotherapy followed by surgery, $\$ 47,389$; and chemoradiotherapy alone, $\$ 46,659$. Treatment-related complications were surgery alone, $47 \%$; chemotherapy followed by surgery, $64 \%$; chemoradiotherapy followed by surgery, $66 \%$; and chemoradiotherapy alone, $87 \%(P=.139)$. Complications increased costs in all groups: surgery alone, $26 \%(P=.008)$; chemotherapy followed by surgery, $23 \%$ $(P=.001)$; chemoradiotherapy followed by surgery, $9 \%(P=.702)$; and chemoradiotherapy alone, $19 \%(P=.248)$.

Conclusions: Costs vary significantly among treatment approaches: surgery alone costs $80 \%$ of chemotherapy and surgery, $71 \%$ of chemoradiotherapy and surgery, and $72 \%$ of chemoradiotherapy alone. Costs of trimodality therapy and definitive chemoradiotherapy are similar. Especially in the absence of definitive evidence-based data, these costs should be a factor in the production of future national treatment guidelines. Decreasing costs requires future quality initiatives in esophageal cancer treatment that focus on minimizing complications related to treatment. (J Thorac Cardiovasc Surg 2011;141:16-21)

The most recent statistics demonstrate that esophageal cancer continues to increase in incidence, especially in men, despite an overall decrease in cancer incidence nationally. ${ }^{1}$ The prognosis associated with esophageal cancer remains poor, and the surgical management of esophageal cancer has historically been associated with a higher incidence of surgical mortality compared with other major oncologic procedures $^{2}$ and complications. ${ }^{3}$ There is a continuing con-

From the Department of Thoracic Surgery and Thoracic Oncology, Virginia Mason Medical Center, Seattle, Wash.

Disclosures: Authors have nothing to disclose with regard to commercial support.

Read at the 36th Annual Metting of The Western Thoracic Surgical Association, Ojai, California, June 23-26, 2010.

Received for publication June 26, 2010; revisions received Aug 26, 2010; accepted for publication Sept 8, 2010; available ahead of print Nov 8, 2010.

Address for reprints: Donald E. Low, FACS, FRCS(c), Section of General Thoracic Surgery, Virginia Mason Medical Center, 1100 Ninth Ave C6-SUR, Seattle, WA 98111 (E-mail: gtsdel@vmmc.org).

$0022-5223 / \$ 36.00$

Copyright $($ C 2011 by The American Association for Thoracic Surgery doi:10.1016/j.jtcvs.2010.09.011 troversy regarding the most appropriate stage-by-stage management of patients with esophageal cancer. ${ }^{4}$ This controversy is intensified in an era when advances in endoscopic treatment techniques, advances in medical and radiation oncology results, and the introduction of minimally invasive surgical procedures make the accumulation of evidencebased data to specifically direct therapy more challenging. Recent in-depth analysis of randomized controlled trials confirms the limited availability of level I evidence to definitively guide therapy in many stages of esophageal cancer. ${ }^{5}$ This has led to significant differences in the approach to esophageal cancer treatment within national and regional health systems, and even between individual practitioners. Patients, government, private payors, and medical systems increasingly are looking to justify the application of limited financial resources. Analysis of outcomes in cancer care has typically focused on disease-free and overall survival, treatment-related complications, mortality, and posttherapy quality of life. The cost of cancer treatment has not typically been a component of outcomes assessment 


$$
\begin{aligned}
& \text { Abbreviations and Acronyms } \\
& \begin{aligned}
\mathrm{CR}= & \text { chemoradiotherapy alone } \\
\mathrm{CRS}= & \text { adjuvant chemoradiotherapy followed by } \\
& \text { surgery } \\
\mathrm{CS}= & \text { adjuvant chemotherapy followed by } \\
& \text { surgery } \\
\mathrm{S} \quad= & \text { surgery alone }
\end{aligned}
\end{aligned}
$$

for a variety of reasons. Most important is the fact that accurate cost data comparing the economic differences in current treatment regimens has not been available. The goal of this study is to accurately document the current true costs associated with surgery, multi-modality therapy, and definitive chemoradiotherapy at the Virginia Mason Medical Center. We believe these data will provide a valuable resource as national treatment guidelines for esophageal cancer continue to evolve and allocation of health care financial resources comes under increasing scrutiny.

\section{MATERIALS AND METHODS}

At a high-volume, tertiary-referral, resident-training esophageal center, the current most common approaches to the treatment of invasive esophageal cancer were identified. These were surgery alone (S), adjuvant chemotherapy followed by surgery (CS), adjuvant chemoradiotherapy followed by surgery (CRS), and chemoradiotherapy alone (CR). In 2000, a financial costaccounting system was introduced (Alliance Decision Support MedAssets, Inc, Atlanta, Ga), allowing individual identification and tracking of all costs associated with treatment. The Alliance Decision Support System allows the Virginia Mason Medical Center to identify all fully loaded costs associated with direct and indirect expenses. Direct costs are broken down to 7 cost components, including salaries and benefits, drugs, and medical supplies. Indirect costs (institution overhead costs) are a complex association of all overhead, including billing, information systems, finance, and administration.

Starting in 2000, 15 consecutive patients in each treatment group who had received their entire treatment at Virginia Mason Medical Center were identified. S, CS, and CRS groups were all treated between 2000 and 2002, whereas the CR group received therapy between 2000 and 2004. All surgical procedures were open transthoracic operations, either left thoracoabdominal or Ivor Lewis. More than $90 \%$ of chemotherapy in all groups during this era typically involves 2 to 4 cycles of cisplatin and 5FU with radiotherapy doses typically of 5940 cGy for the CR group and 4500 to 5040 cGy for the CRS group.

Patient and outcome demographics of the S, CS, and CRS groups were prospectively recorded in an institutional review board-approved database. The CR group was identified through the cancer registry and cancer department database and underwent a retrospective review of their chart and cancer center records.

All inpatient and outpatient costs were recorded from the time of diagnosis to 90 days after completion of therapy. Cost assessment included documenting resources required for diagnosis, staging, primary treatment of esophageal cancer, treatment of complications, and post-treatment follow-up and assessment. The study was reviewed and accepted by our institutional investigational review board.

\section{Statistics}

Descriptive statistical methods were used to evaluate clinical characteristics and cost differences for each management strategy. Each group's cost and relevant clinical characteristics were compared using Student $t$ tests, Pearson's chi-square tests (nonparametric tests), and analysis of variance. Statistical analysis was carried out using the PASW version 18 (SPSS, Inc, Chicago, 11).

\section{The Challenge of Obtaining Accurate Cost Data}

Understanding the cost of delivering medical services is increasingly recognized as an important aspect in the delivery of national medical services and the appropriate use of medical resources. Charges are a poor surrogate $^{6,7}$ for comparison because of significant variance among international, regional, and individual institutions. Many previous cost studies have used cost-to-charge ratios ${ }^{6,8}$ rather than specific cost data for delivering services. Obtaining cost data is likely more straightforward in countries with national or centralized health systems. In the United States, however, there is no central infrastructure to negotiate contracts with suppliers or coordinate treatment approaches or reimbursement. Up to this point, the most accurate method of tracking resource use and costs has been the application of a detailed cost accounting system, such as Transitions System, Inc, which can track resources but assigns estimates of costs. ${ }^{9,10}$

The Alliance costing system has been used at Virginia Mason Medical Center since 2000. The system tracks actual costs but has an 18-month delay until data are complete. This enabled us to examine specific actual costs in our different treatment groups. However, accuracy is contingent on ensuring "all" treatment is delivered in a single medical system. This issue is becoming more pertinent in an era when patients are motivated to travel, often long distances, to high-volume centers for complex cancer therapy. In addition, consistent assessment of costs is more challenging when treatment delivery often occurs over many months and involves multiple medical and surgical subspecialties.

In our study group, which received chemoradiotherapy plus surgery, we had to screen 90 patients to find 15 who had received their entire treatment regimen at Virginia Mason Medical Center and therefore would have a complete cost accounting. Accurate overall assessment of outcomes is best when the cost assessment is done in conjunction with a preexistent prospective database, which was the case in 3 of 4 of our treatment groups.

In addition, considering that the period of assessment typically extends between 4 and 12 months depending on the treatment approach, the cost data must be carefully screened to eliminate nontreatment costs, such as health maintenance or treatment of unrelated conditions. This process is time-intensive, but ultimately leads to the data being as accurate as possible and superior to results obtained in studies using charge-to-cost ratios or extrapolating costs according to relative value units. ${ }^{7}$

\section{RESULTS}

Appropriate consecutive patients were identified in all surgery groups between 2000 and 2002, and the CR group was accrued between 2000 and 2004. During the 3 years in which surgical patients were accrued, a mean of 33 resections per year were performed. Table 1 demonstrates the basic characteristics of each patient group. Except for the expected differences in clinical stage between treatment modalities, there were no significant differences noted in age, gender ratio, presenting body mass index, American Society of Anesthesiologists, or tumor cell type. There was a trend toward a higher incidence of treatment-related complications in the CR group, but this did not reach statistical significance. Hospital length of stay and weight loss more than $10 \mathrm{lbs}$ was significantly greater in the CR group than in the surgical groups. Table 2 shows total costs and 
TABLE 1. Demographics of patients in individual treatment groups

\begin{tabular}{|c|c|c|c|c|c|}
\hline & $\begin{array}{c}\text { Surgery } \\
\text { alone }\end{array}$ & $\begin{array}{l}\text { Chemotherapy } \\
\text { and surgery }\end{array}$ & $\begin{array}{c}\text { Chemoradiotherapy } \\
\text { and surgery }\end{array}$ & $\begin{array}{c}\text { Chemoradiotherapy } \\
\text { alone }\end{array}$ & $\boldsymbol{P}$ \\
\hline Patients (n) & 15 & 15 & 15 & 15 & \\
\hline Mean age (y) & 66 & 60 & 62 & 62 & .103 \\
\hline Age $>65(n)$ & 8 & 6 & 6 & 5 & .729 \\
\hline Male (n) & 13 & 14 & 15 & 14 & .543 \\
\hline ASA 3-5 (n) & 7 & 10 & 11 & 13 & .123 \\
\hline Mean BMI & 27 & 28 & 25 & 23 & .461 \\
\hline $\mathrm{BMI}>30(\mathrm{n})$ & 5 & 4 & 2 & 2 & .449 \\
\hline Pretreatment weight loss $>10 \mathrm{lbs}(\mathrm{n})$ & 3 & 3 & 7 & 11 & .007 \\
\hline Tumor type: adenocarcinoma & 14 & 14 & 15 & 13 & .450 \\
\hline Clinical stage (n) & & & & & .001 \\
\hline I & 8 & & & & \\
\hline II & 5 & 11 & 5 & & \\
\hline III & 2 & 4 & 10 & 7 & \\
\hline IV & & & & 8 & \\
\hline Inpatient hospital days (range) & $8(7-30)$ & $9(6-17)$ & $10(7-18)$ & $14(9-18)$ & .024 \\
\hline Treatment-related complications & 7 & 9 & 10 & 13 & .139 \\
\hline
\end{tabular}

charges for the 4 treatment groups. Costs progressively increased as the number of therapeutic modalities increased, with the $S$ group having the lowest cost $(\$ 33,517)$ and the CRS group being the most expensive $(\$ 47,389)$. Costs-tocharge ratios varied between 2.12 and 2.36, indicating that this methodology could provide an approximate estimation of costs in the absence of specific cost data. However, Table 2 shows that different conversion ratios would be required in our institution between surgical and nonsurgical patients. Surgery alone produced costs equaling $72 \%$ of CR, $80 \%$ of CS, and $71 \%$ of CRS groups. Statistically significant differences were noted in costs between surgery and chemoradiotherapy followed by surgery $(P=.028)$ and between surgery alone and definitive chemoradiation $(P=.015)$. No other significant differences were noted between treatment groups. The costs of the CRS and CR groups were similar: $\$ 47,389$ and $\$ 46,659$, respectively $(P=.907)$.

Table 3 outlines the differences in costs in patients who experience treatment-related complications. As expected, complications increased costs in all treatment groups. Increases were significant in the $\mathrm{S}$ and $\mathrm{CS}$ groups. The failure to identify a significant difference in the cost effect of complications in the other 2 groups is likely related to the relatively small number of patients (CR 2, CRS 5) who did not experience complications at some point during treatment. Individual complications are shown in Table 4. Patients having multiple treatment-related complications were common. No anastomotic or chyle leaks were documented in any of our surgical groups, and no patients died of cancer, treatment-related causes, or unrelated causes during the period of study. The only stage represented in all 4 treatment groups was stage III. However, the number of patients with stage III cancer in groups S (2) and CS (4) was small, making specific comparisons potentially inaccurate.

\section{DISCUSSION}

In an assessment of health care expenditures published in 2010 , the cost of delivering health care in the United States in 2005 was approximately 2 trillion dollars or $16 \%$ of gross domestic product. Health expenditures are increasing at $2 \frac{1}{2}$ times the rate of the general economy, ${ }^{11}$ which is clearly unsustainable. Health care reform and, more pertinently, fiscal requirements will necessitate analyzing cost in addition to standard treatment outcome parameters in future national treatment guidelines and with respect to the future allocation of health care dollars.

This analysis will be more important in treatment regimens for which definitive evidence-based treatment guidelines are unavailable or incomplete, especially in clinical

TABLE 2. Comparison of costs, charges, and cost to charge ratios

\begin{tabular}{|c|c|c|c|c|c|}
\hline Treatment group & Mean cost $(\$)$ & $\begin{array}{c}\text { Standard } \\
\text { deviation }(\$)\end{array}$ & Range (\$) & $\begin{array}{c}\text { Mean } \\
\text { charges }(\$)\end{array}$ & $\begin{array}{c}\text { Cost to charge } \\
\text { ratio } \\
\end{array}$ \\
\hline Surgery alone & 33,517 & 13,059 & $15,584-61,242$ & 78,136 & 2.33 \\
\hline Chemotherapy and surgery & 41,875 & 10,527 & $24,668-58,216$ & 98,763 & 2.36 \\
\hline Chemoradiotherapy and surgery & 47,389 & 19,077 & $22,764-95,955$ & 111,965 & 2.36 \\
\hline Chemoradiotherapy only & 46,659 & 14,592 & $25,410-73,607$ & 98,984 & 2.12 \\
\hline
\end{tabular}


TABLE 3. Effect of complications on costs

\begin{tabular}{|c|c|c|c|c|c|c|c|}
\hline & & & tion & & & & \\
\hline & & & & & & $\%$ increase in overall & \\
\hline & $\mathbf{N}$ & $\begin{array}{l}\text { Mean } \\
\text { cost }(\$)\end{array}$ & $\mathbf{N}$ & $\begin{array}{l}\text { Mean } \\
\text { cost }(\$)\end{array}$ & $\begin{array}{l}\text { Overall mean } \\
\text { cost }(\$)\end{array}$ & $\begin{array}{l}\text { cost for patients } \\
\text { with complications }\end{array}$ & $\boldsymbol{P}$ \\
\hline Surgery alone & 8 & 29,522 & 7 & 38,082 & 33,517 & $25.5 \%$ & .008 \\
\hline Chemotherapy and surgery & 6 & 36,021 & 9 & 45,778 & 41,875 & $23.3 \%$ & .001 \\
\hline Chemoradiotherapy and surgery & 5 & 44,577 & 10 & 48,795 & 47,389 & $8.9 \%$ & .702 \\
\hline Chemoradiotherapy only & 2 & 38,833 & 13 & 47,863 & 46,659 & $19.4 \%$ & .248 \\
\hline
\end{tabular}

conditions that require significant expenditure of health dollars in individual patients.

The stage-by-stage treatment of esophageal cancer remains diverse because of the absence of level 1 evidence to direct therapy ${ }^{4,5}$ and varying regional perceptions of the consequences of surgical therapy., ${ }^{2,3}$ These perceptions have been confirmed with an analysis of the SEER national database confirming that surgery is currently underused in the treatment of all stages of esophageal cancer in the United States. ${ }^{12}$ Individual treatment recommendations can vary significantly depending on the practitioner or medical system a patient initially contacts. Patients with T1a disease may have endoscopic, surgical, or definitive chemoradiotherapy as their initial treatment recommendation. ${ }^{4,13,14}$ As confirmed in this study, patients with stage II or III disease can be recommended for surgery alone, neoadjuvant therapy and surgery, or definitive chemoradiotherapy. ${ }^{5,15,16}$ Patients who are not surgical candidates because of poor physiology may be recommended for chemotherapy, chemoradiation, or palliative care. National Comprehensive

TABLE 4. Number of patients with complications (n)

\begin{tabular}{|c|c|c|c|c|}
\hline & $\begin{array}{c}\text { Surgery } \\
\text { alone }\end{array}$ & $\begin{array}{c}\text { Chemotherapy } \\
\text { surgery }\end{array}$ & $\begin{array}{c}\text { Chemoradiotherapy } \\
\text { surgery }\end{array}$ & $\begin{array}{c}\text { Chemoradiotherapy } \\
\text { alone }\end{array}$ \\
\hline Single complication & 1 & 5 & 4 & 2 \\
\hline Multiple complications & 8 & 4 & 6 & 11 \\
\hline Total complications & 11 & 13 & 16 & 32 \\
\hline \multicolumn{5}{|l|}{ Cardiac } \\
\hline Atrial fibrillation & 1 & 4 & 3 & 2 \\
\hline MI & & & & 1 \\
\hline $\mathrm{CHF}$ & & & & 2 \\
\hline Pericardial effusion & & & & 2 \\
\hline \multicolumn{5}{|l|}{ Pulmonary } \\
\hline Pneumonia & 1 & 1 & & 5 \\
\hline \multicolumn{5}{|l|}{ Pleural Eff } \\
\hline Req Rx & 1 & 2 & 2 & 2 \\
\hline \multicolumn{5}{|l|}{ Pneumothorax } \\
\hline Req Rx & 1 & & 1 & \\
\hline Reintubation & & & 1 & \\
\hline Respiratory failure & & & & 1 \\
\hline Other & & & & 1 \\
\hline \multicolumn{5}{|l|}{ GI } \\
\hline Ileus & 2 & 1 & & \\
\hline SBO & & 1 & & \\
\hline GI bleeding & & & & 1 \\
\hline Urinary & 1 & 2 & 1 & \\
\hline Delirium & 3 & & 3 & \\
\hline Wound infection & & 2 & 2 & \\
\hline Reoperation & 1 & & & \\
\hline Dehydration & & & & 4 \\
\hline Hematologic & & & & 4 \\
\hline Vascular (DVT/PE) & & & 2 & 2 \\
\hline Other & & & 1 & 5 \\
\hline
\end{tabular}

$M I$, Myocardial infarction; $C H F$, congestive heart failure; $S B O$, small bowel obstruction; $G I$, gastrointestinal; $D V T / P E$, deep vein thrombosis/pulmonary embolism. 
Cancer Network guidelines exist to direct therapy in patients with cancer. ${ }^{17}$ However, the consistency of the delivery of treatment in esophageal cancer within the United States remains open to individual interpretation, and current guidelines do not typically include costs in the formulation of the recommendations often because accurate data do not exist.

Surgical treatment of esophageal cancer has experienced particular scrutiny within medical circles but also by consumer groups, such as Leapfrog (www.leapfrog.com), because of higher levels of complications ${ }^{3}$ and mortality. ${ }^{2}$ Previous studies have clearly demonstrated that complications increase the cost of therapy. ${ }^{8,9,18-21}$ Other reports highlight that comorbidities and surgical complexity also lead to higher costs, ${ }^{18}$ which is particularly germane in patients treated for esophageal cancer.

Limiting complications is clearly a major factor in controlling costs. Dimick and colleagues ${ }^{9}$ showed the financial impact of complications in a wide variety of surgical procedures at a single medical center involved in the National Surgery Quality Improvement Program. Consistent with our findings, they demonstrate that major complications increase costs an average of more than $\$ 11,000$. They appropriately concluded that quality initiatives that minimize the incidence of complications would have a direct effect on treatment-related costs. ${ }^{19}$ Previous cost assessments in the treatment of esophageal cancer have been of limited application because they focus on only a component of the treatment options or cost data are estimated or incomplete. ${ }^{20}$

The results of the current study are taken from actual costs of delivering the specified treatment. This is an extremely labor-intensive process and not applicable in larger single-center or national database reviews, but in this instance it does provide a rare insight into actual costs of the 4 current treatment approaches to invasive esophageal cancer at Virginia Mason Medical Center. Except for differences in clinical stage, the 4 groups were similar.

There is a perception that chemoradiation therapy is safer than surgical treatment. In addition, esophagectomy has a well-earned reputation for post-treatment complications. It is possible that some of the cost and complications differences noted, especially in the CR group, were associated with more advanced stage and poorer performance status, as reflected in greater pretreatment weight loss (Table 1). However, all 3 surgical groups had numerically fewer treatment-related complications than the definitive chemoradiation group. The definitive chemoradiotherapy group did have significantly greater pretreatment weight loss than the surgical groups; however, the CR group also required significantly more in-hospital days than the groups receiving surgery alone or multimodality treatment. The $\mathrm{S}$ group had the lowest overall incidence of complications and generates costs only $72 \%$ of those seen in definitive chemoradiotherapy.
There is an evolving interest in comparing surgery alone with definitive chemoradiotherapy in all stages of esophageal cancer, but particularly in early stage I and IIA. ${ }^{15}$ Mak and colleagues ${ }^{21}$ documented that, especially in older patients, chemoradiation can be associated with grade IV toxicity in $40 \%$ and hospitalizations and treatment interruptions in $70 \%$. They also showed that in patients aged more than 75 years, the mortality rate was $12 \%$, which is higher than seen in comparable surgical series. ${ }^{22,23}$ Our data suggest that even while acknowledging differences in stage and performance status in specialized centers, surgery has a potential advantage from the perspective of treatment-related complications, hospital length of stay, and costs. This issue should be part of future comparisons of these 2 treatment approaches. Mortality could not be assessed, because there were no deaths in any treatment group during this study.

Surgery alone also used fewer resources and cost only $80 \%$ of chemotherapy plus surgery and $71 \%$ of chemoradiation plus surgery. Although current treatment trends in North America and Europe favor neoadjuvant treatment, the most recent reviews of best available evidence are not definitive in their support of multi-modality treatment. ${ }^{5,24}$ Future formulation of national treatment guidelines should include assessments of cost-effectiveness, as well as treatment efficacy and safety.

In the shorter term, however, payors are likely to demand a more specific cost assessment of treatment approaches, especially when definitive treatment guidelines do not exist or are not supported by evidence-based clinical data. Current growth in health care expenditures is not sustainable in the long-term. ${ }^{11}$ This issue goes further than simple cost analysis because, increasingly, measurements of treatment outcomes are focusing on regional and national assessments of quality, which are directly associated with limiting the incidence of treatment-related complications. ${ }^{9,19}$ The current study demonstrates that complications increase costs between $9 \%$ and $25 \%$. Patients with treatment-related complications consume more resources and demonstrate higher mortality rates and poorer post-treatment quality of life. ${ }^{3,19}$ Under diagnosis-related group and capitated reimbursement programs, complications affect institutional and medical system profit margins, but the greatest burden has historically fallen on payors, both government and private, who experience increased costs when complications occur. ${ }^{19}$ However, there is an increasing trend toward shifting this burden more toward medical systems. This is most evident with the Centers for Medicare and Medicaid Services' recent passage of hospital-acquired conditions legislation and the subsequent adoption of the payment provision(s) by major insurance companies. ${ }^{25-27}$ In the future, payors (both government and private) will increasingly use quality and cost data to guide decisions regarding health-related resource allocation, especially in high-risk 
and high-cost clinical conditions. This may include directing patients to recognized centers of excellence that can demonstrate the ability to limit complications and control cost expenditures. It may also be an instigating factor for individual medical systems deciding which highly complex medical procedures they will provide.

The potential weakness of this study is the relatively small number of patients in each study group. However, our goal was to provide an actual rather than estimated indication of true costs. This assessment included only patients who had their entire treatment at a single medical center, which, considering the complexity of current treatment and the increasing use of regional referral centers, is becoming more uncommon. These patients had assessment of all inpatient, outpatient, direct, and indirect costs, and underwent a labor-intensive screening to remove all nontreatment-related costs, resulting in this report providing a financial perspective more accurate than its predecessors.

\section{CONCLUSIONS}

This study provides as accurate as possible expression of the true costs of the various treatment approaches to esophageal cancer and confirms the significant economic effect of complications on the cost of delivering treatment. These data should be considered in the continued evolution of national treatment guidelines for the treatment of esophageal cancer.

\section{References}

1. Jemal A, Siegel R, Ward E, Hao Y, Xu J, Thun MJ. Cancer statistics, 2009. CA Cancer J Clin. 2009;59:225-49.

2. Birkmeyer JD, Siewers AE, Finlayson EV, Stukel TA, Lucas FL, Batista I, et al. Hospital volume and surgical mortality in the United States. N Engl J Med. 2002; 346:1128-37.

3. Dimick JB, Pronovost PJ, Cowan JA Jr, Lipsett PA, Stanley JC, Upchurch GR Jr. Variation in postoperative complication rates after high-risk surgery in the United States. Surgery. 2003;134:534-40.

4. Iyer R, Wilkinson N, Demmy T, Javle M. Controversies in the multimodality management of locally advanced esophageal cancer: evidence-based review of surgery alone and combined-modality therapy. Ann Surg Oncol. 2004;11: 665-73.

5. Barnett SA, Rizk NP. Randomized clinical trials in esophageal carcinoma. Surg Oncol Clin N Am. 2010;19:59-80.

6. Chrischilles EA, Scholz DA. Dollars and sense: a practical guide to cost analysis for hospital epidemiology and infection control. Clin Perform Qual Health Care. 1999;7:107-11.

7. Shwartz M, Young DW, Siegrist R. The ratio of costs to charges: how good a basis for estimating costs? Inquiry. 1995;32:476-81.
8. Ferraris VA, Ferraris SP, Singh A. Operative outcome and hospital cost. J Thorac Cardiovasc Surg. 1998;115:593-602.

9. Dimick JB, Chen SL, Taheri PA, Henderson WG, Khuri SF, Campbell DA Jr. Hospital costs associated with surgical complications: a report from the private-sector National Surgical Quality Improvement Program. J Am Coll Surg. 2004;199:531-7.

10. Pronovost P, Angus DC. Cost reduction and quality improvement: it takes two to tango. Crit Care Med. 2000;28:581-3.

11. Munoz E, Munoz W III, Wise L. National and surgical health care expenditures, 2005-2025. Ann Surg. 2010;251:195-200.

12. Paulson EC, Ra J, Armstrong K, Wirtalla C, Spitz F, Kelz RR. Underuse of esophagectomy as treatment for resectable esophageal cancer. Arch Surg. 2008;143: 1198-203.

13. Manner H, May A, Pech O, Gossner L, Rabenstein T, Gunter E, et al. Early Barrett's carcinoma with "low-risk" submucosal invasion: long-term results of endoscopic resection with a curative intent. Am J Gastroenterol. 2008;103:2589-97.

14. Yamada K, Murakami M, Okamoto Y, Okuno Y, Nakajima T, Kusumi F, et al Treatment results of chemoradiotherapy for clinical stage I (T1NOM0) esophageal carcinoma. Int J Radiat Oncol Biol Phys. 2006;64:1106-11.

15. Abrams JA, Buono DL, Strauss J, McBride RB, Hershman DL, Neugut AI. Esophagectomy compared with chemoradiation for early stage esophageal cancer in the elderly. Cancer. 2009;115:4924-33.

16. Suntharalingam M. Definitive chemoradiation in the management of locally advanced esophageal cancer. Semin Radiat Oncol. 2007;17:22-8.

17. The NCCN Clinical Practice Guidelines in Oncology (NCCN Guidelines ${ }^{\mathrm{TM}}$ ) Esophageal Cancer (Version 1.2010). () 2010 National Comprehensive Cancer Network, Inc. Available at: NCCN.org. Accessed May 24, 2010.

18. Davenport DL, Henderson WG, Khuri SF, Mentzer RM Jr. Preoperative risk factors and surgical complexity are more predictive of costs than postoperative complications: a case study using the National Surgical Quality Improvement Program (NSQIP) database. Ann Surg. 2005;242:463-8.

19. Dimick JB, Pronovost PJ, Cowan JA, Lipsett PA. Complications and costs after high-risk surgery: where should we focus quality improvement initiatives? $J A m$ Coll Surg. 2003;196:671-8.

20. Dimick JB, Weeks WB, Karia RJ, Das S, Campbell DA Jr. Who pays for poor surgical quality? Building a business case for quality improvement. $J \mathrm{Am}$ Coll Surg. 2006;202:933-7.

21. Mak RH, Mamon HJ, Ryan DP, Miyamoto DT, Ancukiewicz M, Kobayashi WK, et al. Toxicity and outcomes after chemoradiation for esophageal cancer in patients age 75 or older. Dis Esophagus. 2010;23:316-23. Epub 2009 Sep 24.

22. Ma JY, Wu Z, Wang Y, Zhao YF, Liu LX, Kou YL, et al. Clinicopathologic characteristics of esophagectomy for esophageal carcinoma in elderly patients. World J Gastroenterol. 2006;12:1296-9.

23. Ruol A, Portale G, Castoro C, Merigliano S, Cavallin F, Battaglia G, et al. Management of esophageal cancer in patients aged over 80 years. Eur J Cardiothorac Surg. 2007;32:445-8

24. Raja SG, Salhiyyah K, Nagarajan K. Does neoadjuvant chemotherapy improve survival in patients with resectable thoracic oesophageal cancer? Interact Cardiovasc Thorac Surg. 2007;6:661-4.

25. Hospital-Acquired Conditions, Centers for Medicare \& Medicaid Services, Baltimore, MD. Available at: https://www.cms.gov/HospitalAcqCond/06_HospitalAcquired_Conditions.asp. Accessed June 10, 2010.

26. Health Law Perspectives (June 2008), University of Houston's Health Law and Policy Institute. Available at: http://www.law.uh.edu/healthlaw/perspectives/ 2008/(BP)\%20errors.pdf. Accessed June 10, 2010.

27. Medicare's Big Changes: moving to a payment system tied to the severity of illness and refusing to pay for hospital-acquired conditions may encourage private payers to do the same. Managed Care Magazine, May 2008. Available at http://www. managedcaremag.com/archives/0805/0805.msdrg.html. Accessed June 10, 2010. 